\title{
BMJ Open Multiple factor analysis of eating patterns to detect groups at risk of malnutrition among home-dwelling older subjects in 2015
}

\author{
Marc-Antoine Sanchez, ${ }^{1}$ Didier Armaingaud, ${ }^{2}$ Yasmine Messaoudi, ${ }^{2}$ Aude Letty, ${ }^{2}$ \\ Rachid Mahmoudi, ${ }^{\oplus, 4}$ Stéphane Sanchez ${ }^{\oplus 5}$
}

To cite: Sanchez M-A, Armaingaud D, Messaoudi Y, et al. Multiple factor analysis of eating patterns to detect groups at risk of malnutrition among home-dwelling older subjects in 2015. BMJ Open 2019;9:e023548. doi:10.1136/ bmjopen-2018-023548

- Prepublication history and additional material is published online only. To view please visit the journal online (http://dx.doi. org/10.1136/bmjopen-2018023548).

Received 8 June 2018 Revised 3 June 2019

Accepted 12 June 2019

Check for updates

(c) Author(s) (or their employer(s)) 2019. Re-use permitted under CC BY-NC. No commercial re-use. See rights and permissions. Published by BMJ.

${ }^{1}$ Department of epidemiological surveillance, French Armed

Forces Centre for Epidemiology and Public Health (CESPA),

Marseille, France

${ }^{2}$ Department of clinical research, Fondation Korian pour le bien vieillir Paris, France

${ }^{3}$ Department of Geriatrics and Internal Medicine, Reims

University Hospital, Reims,

France

${ }^{4}$ Faculty of Medicine, University of Reims Champagne Ardennes, Reims, France

${ }^{5}$ Hospital of Troyes, Information and Medical Assessment Unit, Troyes, France

Correspondence to

Dr. Marc-Antoine Sanchez; eomsanchez@hotmail.com

\section{ABSTRACT}

Objective We aimed to describe eating patterns among home-dwelling older subjects to establish typologies of eaters at higher or lower risk of malnutrition.

Design Cross-sectional study between June and September 2015 using a standardised questionnaire. The questionnaire was given to home-help employees (responsible for delivering meals to home-dwelling older persons and helping them to eat). The employees were asked to complete the questionnaire three times during the same week, for the same older adults, in order to identify the totality of their food intake.

Setting Registered customers of the home meal delivery company 'Azaé' (France).

Participants 605 older home-dwelling persons were randomly selected among customers served by the home meal delivery company.

Outcomes Multiple factor analysis was used to understand the different modes of food consumption and to establish eating profiles. Hierarchical classification was performed to construct eating profiles corresponding to the dietary habits of the respondents.

Results Average age of the older adults was 85.3 years; $73.5 \%$ were women. Overall, $59 \%$ of participants reported that they ate out of habit, while $33.7 \%$ said they ate for pleasure. We identified four different groups of eaters, at varying levels of risk for malnutrition. Individuals in group 4 had the highest food intake in terms of quantity; and were less dependent than individuals in group $1(\mathrm{p}=0.05)$; group 1 was at highest risk of malnutrition.

Conclusion Improved understanding of eating habits can help detect risky behaviours and help caregivers to promote better nutrition among home-dwelling older subjects.

\section{INTRODUCTION}

Addressing nutrition issues is an integral part of managing older adults, not only those living in long-term care facilities but also among home-dwelling older adults. Malnutrition can accentuate sarcopenia, contribute to loss of autonomy and increase the risk of falls, fracture, neurodegenerative disease and even death. ${ }^{1-5}$ Malnutrition also causes older
Strengths and limitations of this study

- The questionnaire was completed on three non-consecutive weekdays, in order to be representative of usual habits, and to avoid exceptional situations huge. It contained meals but also sociodemographic data; contents of the person's refrigerator, to more finely describe eating habits.

- Multiple factor analysis enables geometric representation of sets of variables, and is established as a robust method for identifying similarities and differences between the characteristics of the individuals.

- This method identifies different profiles, but does not explain the totality of the variance.

adults to have greater difficulty returning to their former weight, partly due to loss of appetite, ${ }^{6}$ and can be exacerbated by unfavourable socioenvironmental factors. ${ }^{7}$ Conversely, satisfactory nutrition in older adults is associated with a reduced risk of cognitive decline or Alzheimer's disease. ${ }^{9}$ Preventing the possible consequences of malnutrition is therefore clearly a priority for public health policies. Although several instruments are available to detect risk of malnutrition, such as Mini Nutritional Assessment or the Simplified Evaluation of Food Intake (SEFI) instrument, and are widely used in the in-hospital setting, ${ }^{10} 11$ or during consultations in private geriatrics practices, ${ }^{101213}$ no study to date has focused on the quantitative and qualitative characteristics of food intake among community-dwelling older adults.

Currently, guidelines from professional societies recommend protein intake in the range of $1-1.2 \mathrm{~g} / \mathrm{kg} /$ day for healthy older adults, ${ }^{1} 1415$ and up to $1.5-2.0 \mathrm{~g} / \mathrm{kg} /$ day in case of injury or disease predisposing to malnutrition. The metabolic specificities of older adults can disrupt appetite or energy and protein metabolism. Therefore, older 
adults are at greater risk of insufficient or inappropriate dietary intake, ${ }^{1617}$ and combatting malnutrition is a key preventive measure to ensure successful ageing. ${ }^{18} 19$ Indeed, it has been shown in the literature that socioeconomic factors as well as sex play an important role among the different dietary patterns observed in older adults. ${ }^{2021}$

In this context, closer investigation of diet among older adults living at home, and potentially at risk of admission to a nursing home, to identify nutritional profiles, would shed light on this topic. Our main aim was therefore to describe dietary intake in older adults living at home with a view to establishing typologies of eaters at higher or lower risk of malnutrition. Secondary objectives were to analyse refrigerator contents according to the typologies previously defined and to identify foods that would make it possible to improve dietary intake in older adults at risk of malnutrition.

\section{METHODS}

We performed a cross-sectional study between June and September 2015 using a standardised questionnaire, among older adults living at home, chosen at random from among registered customers of the home meal delivery company 'Azaé' (France). The homehelp employees are responsible for delivering meals to home-dwelling older adults and helping them to eat. They are acutely aware of the importance of the nutrition and are trained to detect any malnutrition disorders. All participants were recruited by the employees of the home delivery service, three times during the same week, for the same older adult, in order to identify the totality of their food intake. They were asked to complete the questionnaire on three non-consecutive weekdays, and not at the weekend, in order to be representative of usual habits, and to avoid exceptional situations such as family occasions or visits from relatives or family members. Data were anonymous data, in accordance with current French legislation relating to observational, non-interventional clinical research in France, namely articles L.1121-1 and R.1121-2 of the Code of Public Health. Accordingly, written informed consent was not required from participants, and the ethics committee approval was not required. This study was performed in accordance with current legislation relating to data privacy and received the approval of the national authority for the protection of privacy and personal data (Commission Nationale Informatique et Libertés).

The questionnaire comprised six sections, covering sociodemographic data; the contents of the person's refrigerator (inventoried by the home-help); meals of the older adult (three main meals of the day), but also any snacks and/or aperitifs. The time meals were taken, how the meal was taken, and the older adult's food preferences were also recorded. To take account of the potential role of external factors, questions relating to the socioeconomic level of the older adults were also included. The questionnaires were completed on three different, non-consecutive days in order to record a maximum amount of data, and to make it possible to observe any changes in food intake.

All subjects living at home and receiving home meal delivery could be included. Participants were spread across all of France, and all levels of autonomy were represented.

After a descriptive analysis of the subjects' characteristics and food intake, multiple factor analysis (MFA) was performed to understand the different modes of food consumption and establish profiles. Multiple factor (or factorial) analysis is a statistical method that enables geometric representation of sets of variables, with a view to identifying similarities and differences between the characteristics of the individuals. The advantage of MFA is that it takes into account groups of variables, which was of particular interest in our study. For example, we wanted to identify the characteristics of breakfast, lunch and dinner separately. Moreover, we can also take account of relations between groups of these variables. We hypothesised that dietary habits would depend on the pleasure of eating, the area of residence and the level of autonomy.

Information relating to the quantity of each food consumed by each participant was summarised by calculating the mean consumption of each food over the 3 days of data recording by scoring 1 or 0 according to whether the food was consumed or not, respectively. Thus, a food consumed on all 3 days scored 1; a food consumed 2 out of 3 days scored 0.66 , and a food consumed on 1 out of 3 days scored 0.33. Data were grouped into four categories: breakfast, lunch, snack and dinner. Variables included in the MFA are described in online supplementary table S1. Each of these groups was considered as an active group in the factorial analysis. To aid interpretation, additional variables were used, namely sex, type of residence, marital status, income, dietary habits and whether the person was a beneficiary of the social welfare allocation for autonomy (a government contribution to finance the cost of homehelp services, including in particular cleaning services or home meal deliveries to allow older adults to remain living at home).

MFA was performed for each of the variables of interest. Certain variables were grouped when numbers of responses were small.

Hierarchical classification was then performed to construct eating profiles corresponding to the dietary habits of the respondents. Subgroup analysis was also performed to investigate more nuanced differences in eating behaviours. Finally, the contents of the respondent's refrigerator were described, in light of the results of the MFA. All variables have been described in online supplementary table S2.

All analyses were performed using R software V.3.3.2, FactoMineR and Factoshiny packages. A p value of $<0.05$ was considered statistically significant. 


\section{Patient and public involvement}

One of our goals was less to detect malnutrition than to prevent it, which means having some knowledge of eating habits to distinguish certain risk behaviours. Thus, we were more interested in people who do not suffer from malnutrition to describe the potential threshold beyond which the state of malnutrition occurs. Participants were not directly involved in the design of the study. The main results will be communicated to the home-help employees, who may in turn relay the results to the patients.

\section{RESULTS}

\section{Study population}

A total of 605 home-dwelling older persons were randomly selected among those served by the home meal delivery company. The characteristics of the participants, and their dietary habits are described in table 1.

Average age was $85.3 \pm 5$ years (range $67-100$ ); $73.5 \%$ were women, $70.1 \%$ lived in urban areas and $42.6 \%$ had an income between 1000 and $2000 €$ per month. Overall, $59 \%$ of participants reported that they ate out of habit, while $33.7 \%$ said they ate for pleasure. Online supplementary table 1 shows the list of foods and drinks recorded for the different meals during the day. Online supplementary table 2 shows the list of variables recorded for refrigerator contents.

\section{MFA: different eating profiles}

The results of the MFA are presented in figure 1. The first axis represents the qualitative nature of food consumption; for example, some foods are consumed systematically out of habit (such as having a hot drink with breakfast), whereas others less so (eg, having a treat after dinner). The second axis represents the cumulative character of the food consumed. This axis indicates opposition for certain variables of the breakfast and snack variables as compared with the other meals. In particular, individuals who ate a large breakfast also had higher snack intake than other groups.

Online supplementary figures S1-S3 show the results according to the explanatory variables. By selecting only individuals most representative of each axis, those who ate for pleasure had more copious breakfasts and snacks than those who ate out of habit. Participants living in rural areas and those in urban areas were opposed in both axis 1 and axis 2. Those who lived in rural areas ate more, including for breakfast and snacks.

\section{Ascending hierarchical classification: description of clusters of eaters}

Our results identify four groups that can be interpreted according to the axes described in the MFA (table 2). Group 1 comprised 62 individuals $(10.3 \%)$, group 2 comprised $208(34.4 \%)$, group 3 comprised 167 (27.6\%) and group 4 comprised 168 individuals $(27.7 \%)$. The four groups are presented in table 2. All the food variables shown showed significant distribution differences
Table 1 Characteristics of the study population of 605 home-dwelling older adults

\begin{tabular}{|c|c|}
\hline Variables & n (\%) \\
\hline Age, years (mean $\pm S D)$ & $85.3 \pm 5$ \\
\hline \multicolumn{2}{|l|}{ Sex } \\
\hline Female & $433(73.5)$ \\
\hline Male & $155(26.5)$ \\
\hline \multicolumn{2}{|l|}{ Area of residence } \\
\hline Urban & $424(70.1)$ \\
\hline Rural & $181(29.9)$ \\
\hline \multicolumn{2}{|l|}{ Marital status } \\
\hline Living alone & $372(61.5)$ \\
\hline Living maritally & $233(38.5)$ \\
\hline \multicolumn{2}{|l|}{ Monthly income } \\
\hline$<1000 €$ & 117 (19.3) \\
\hline $1000-2000 €$ & $258(42.6)$ \\
\hline$>2000 €$ & $230(38.1)$ \\
\hline \multicolumn{2}{|l|}{ Isoresource group* } \\
\hline 1 & $14(3.8)$ \\
\hline 2 & $68(18.4)$ \\
\hline 3 & $108(29.3)$ \\
\hline 4 & $153(41.5)$ \\
\hline 5 & $23(6.2)$ \\
\hline 6 & $3(0.8)$ \\
\hline \multicolumn{2}{|l|}{ Eating pattern } \\
\hline Out of habit & $357(59)$ \\
\hline For the pleasure of eating & $204(33.7)$ \\
\hline Out of duty & $44(7.3)$ \\
\hline $\begin{array}{l}\text { Beneficiary of social welfare } \\
\text { allocation for autonomy }\end{array}$ & $366(64.4)$ \\
\hline $\begin{array}{l}\text { Amount of social welfare allocation } \\
\text { per month, } €(\text { mean } \pm S D)\end{array}$ & $376.5 \pm 276.9$ \\
\hline
\end{tabular}

*Isoresource group is a measure of autonomy used in France; level 1 corresponds to the greatest loss of autonomy (ie, most dependent) and level 6 to the least loss of autonomy (ie, least dependent).

between groups, and significant differences from the mean, of at least $5 \%(\mathrm{p}<5 \%)$.

Group 1 ate less at all meals than the other groups. The social welfare allocation variable was related to group 1 . Group 1 was at highest risk of malnutrition since all foods were consumed at a level below the overall mean for all participants. In this group, proteins at lunch and dinner, as well as carbohydrates were consumed at less than one meal out of two. To facilitate interpretation of the results, we considered individuals in group 1 to have the highest risk profile for malnutrition.

Individuals in group 2 consumed more hot drinks at breakfast and for snacks, but generally ate less at all meals, particularly less fruit. Group 2 could be considered 


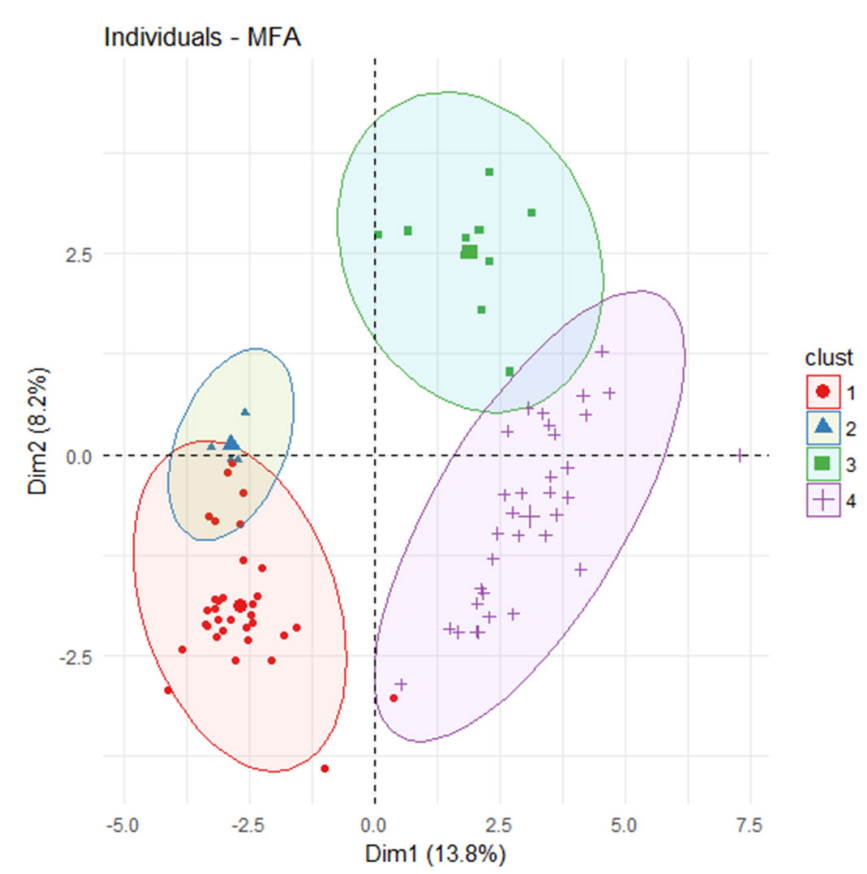

Figure 1 Results of MFA by typologies of eaters from 605 elderly home-dwelling persons. The first axis represents the qualitative nature of food consumption; for example, some foods are consumed systematically out of habit; the second axis represents the cumulative character of the food consumed. MFA, multiple factor analysis.

at moderate risk of malnutrition. Lunch and dinner were generally light meals, with low protein intake. We thus considered individuals in group 2 to have a moderate risk profile for malnutrition.

Group 3 generally ate better at all meals, notably with more fruit, vegetables and proteins. They consumed fewer cold drinks. We thus considered the individuals in this group as having a normal profile, since the quantity of food intake met the recommendations for daily nutritional intake.

Group 4 ate greater quantities of all foods than did the individuals in group 3. Accordingly, group 4 had the most varied and the most copious diet, and was thus at least risk of malnutrition, consuming more overall, particularly in terms of fruit, vegetables and dairy products. Group 4 also corresponded to the least dependent participants. We thus considered this group as the 'ideal profile'.

\section{Characteristics of the refrigerator contents according to eating profile}

The significant differences in refrigerator contents between the different profiles are detailed in table 2 . There were significant differences between profiles in terms of protein sources like yoghurt, meat and soured cream.

\section{Socioeconomic characteristics of participants}

Table 3 summarises the main socioeconomic characteristics. There was no significant difference in age between groups $(\mathrm{p}=0.6)$. However, group 4 had higher wine consumption than the overall average $(p<0.05)$, while group 1 had lower consumption than the overall mean $(p \leq 0.001)$. There was a significant difference in terms of the social welfare allocation for autonomy, whereby the better the eating profile of the group, the less it tended to receive the social welfare allocation for autonomy $(p=0.05)$. There was no significant difference in the other participant characteristics.

\section{DISCUSSION}

The results of this MFA provide new insights into food consumption among older adults. The first axis identified the type of foods that are staple foods and always consumed, while the second axis shows opposition in the eating profiles, with, on the one hand, individuals who eat two meals per day and a light breakfast, and on the other hand, those who have four meals a day, including copious and well-balanced breakfast and snacks. These findings underline that there is wide diversity in the ways older adults eat, both qualitatively and quantitatively. This difference should nonetheless be interpreted in light of the characteristics of our study population, which comprised mainly women, of middle to upper socioeconomic class, mostly living alone and in urban areas. This type of population spontaneously adopts more healthy dietary behaviours than the general population of elderly subjects. $^{20}$

Our results identified different eating profiles, established according to the quantity of food ingested as compared with the overall mean of the study population, and in terms of the refrigerator contents. In this context, the group with the highest risk profile for malnutrition had mainly protein-based foods in the refrigerator, in quantities at least as great as those observed in the ideal profile group, but the food goes uneaten. This is coherent with previous reports in the literature showing that to continue nourishing themselves, older adults must either want to eat or feel the need to eat. ${ }^{22}$

The individuals at moderate and high risk of malnutrition most frequently had only two meals a day, which is insufficient according to current guidelines for daily intake in older adults. ${ }^{23}$ The dietary patterns in the group with the ideal profile is very close to that recommended by the guidelines, notably with high consumption of dairy products and foods rich in vitamins, particularly at snack time. The group with the 'normal' profile had a well-balanced diet, including fruit and vegetables, which is known to be associated with reduced mortality and improved health in older adults. ${ }^{16}$

Knowing each individual's profile will make it possible to propose foods that are most adopted to that person's eating pattern. Each group could receive specific dietary advice from the home meal-delivery service or from the primary caregiver. In the groups at moderate and high risk of malnutrition, advice regarding the quantity of food eaten could place emphasis on increasing consumption of proteins, especially for dinner, while at the same 


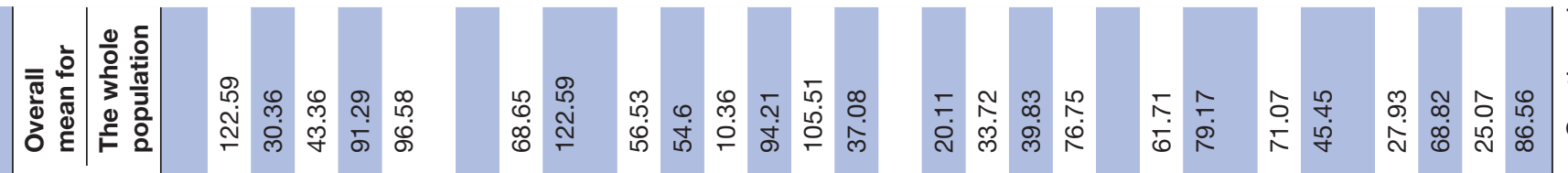

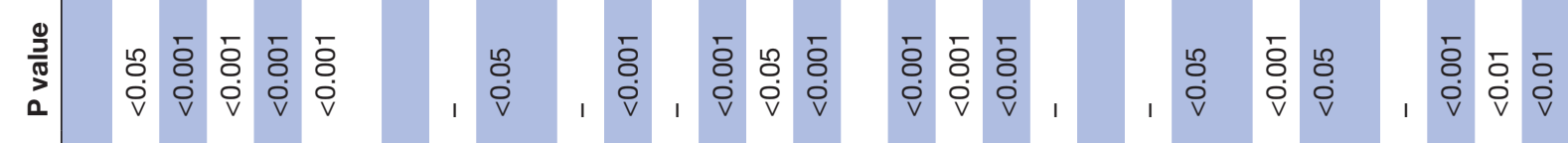

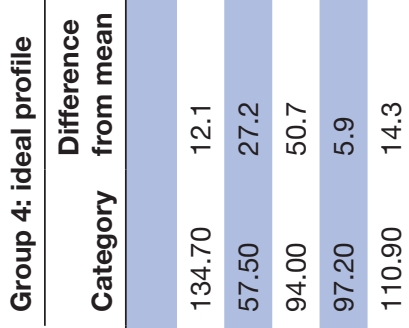

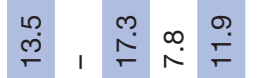

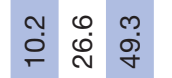

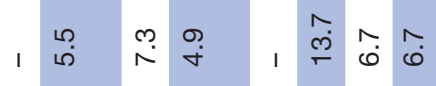

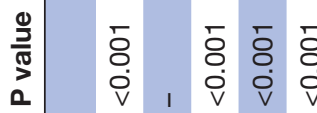

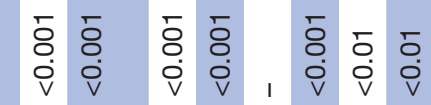

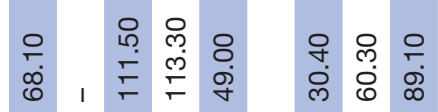

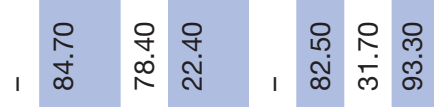

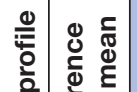

है

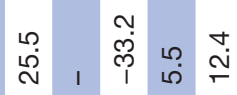

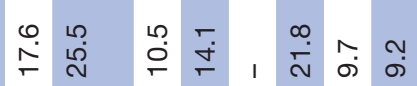

훙

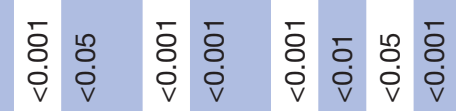

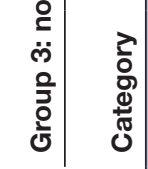

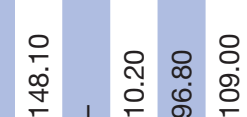

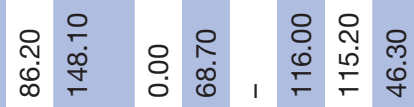

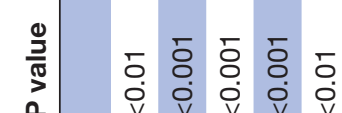

Бे

웅

$\overline{8}$
v
v

๑

ำ ำ 웅

이 오 웅

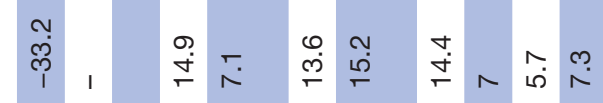

๑ $\frac{1}{\circ}$

(0)

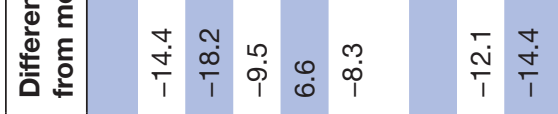

$\frac{1}{20}$

$\begin{array}{llll}\overline{8} & \overline{0} & \overline{0} & \overline{8} \\ 0 & 0 & 0 \\ 0 & 0 & 0 & 0\end{array}$

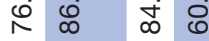

ช ผ

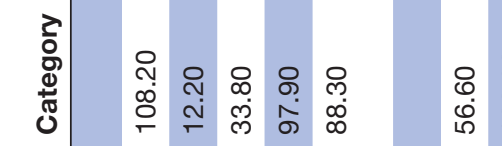

0
0
$i$
$i$
$i$

8

8

ลุ

œ 우 \& 8 8

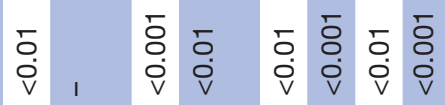

4

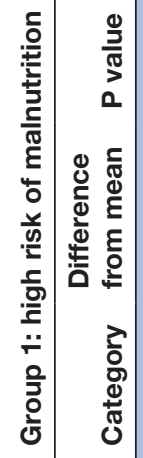

$\overline{8}$

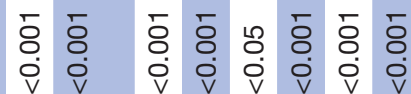

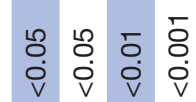

$\begin{array}{ll}\overline{0} & \overline{8} \\ \text { oे } & 0 \\ \text { v }\end{array}$

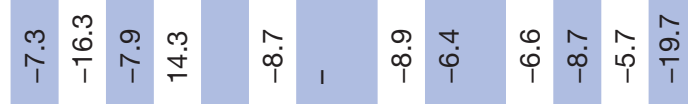

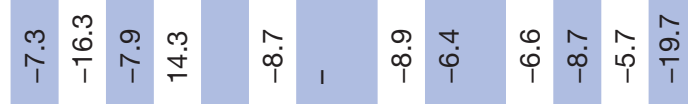

ํํํ

กึ ।

오으

아 으 우 우

ชิ่ में ठं

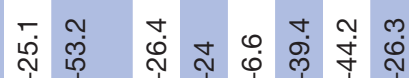

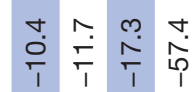

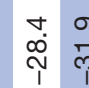

$\overline{8} \overline{8}$

누 $\overline{0} \overline{0}$ 1 1 1 की

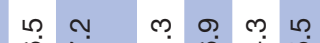

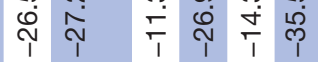

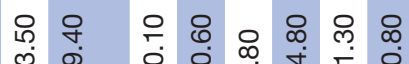

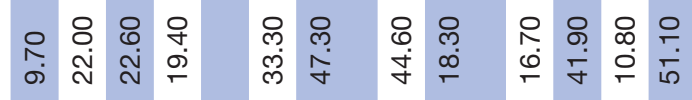

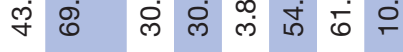

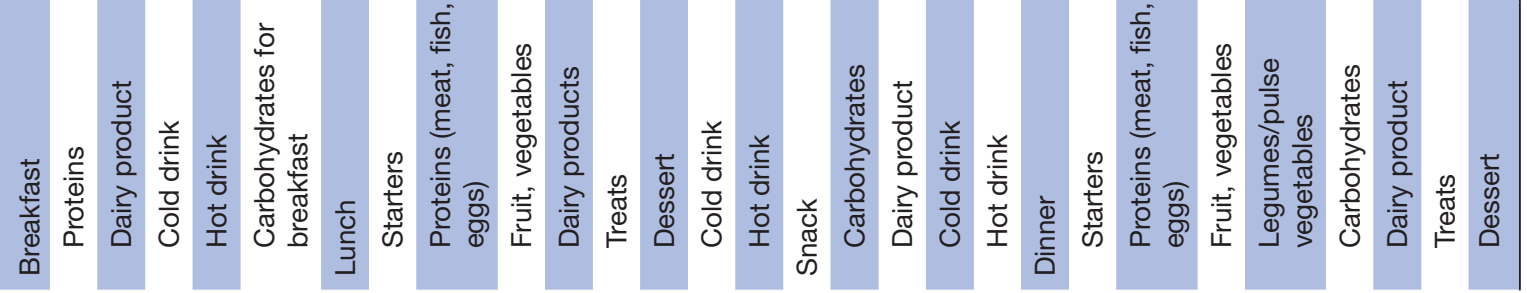




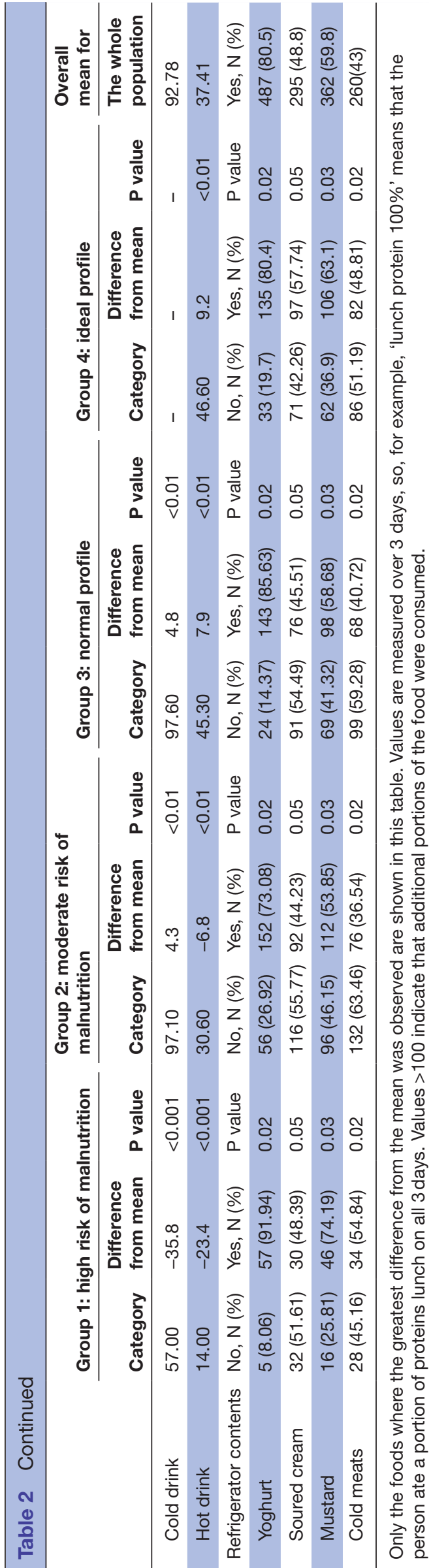

time maintaining the pleasure of eating. Conversely, in the groups with a normal or 'ideal' profile, whose intake is sufficient in quantitative terms, dietary advice could focus on the importance of drinking enough fluids, and they might also be encouraged to maintain a high level of fruit and vegetable intake.

Our results indicate that the social welfare allocation to older adults to maintain autonomy is a factor that distinguishes risk groups, namely those at moderate and high risk versus those at lower risk (normal and ideal profiles). In this regard, one finding in our study that is in line with the existing literature, is that the more dependent patients are, the higher the risk of malnutrition. ${ }^{21}{ }^{24}$ This underscores the validity of the risk profile groups identified here.

Our findings also reveal that only a small percentage of community-dwelling older adults eat for the pleasure of eating. This is coherent with previous reports that reinforcing the hedonic aspect of meals ${ }^{25}$ was found to be determinant in pursuing balanced nutrition. ${ }^{23}$ Furthermore, the pleasure of eating can also help to promote intake in the event of behaviours at risk of malnutrition. Whether for iatrogenic or physiological reasons, or as a result of disease, the sense of taste and smell can be altered in older adults. Yet, these senses are fundamental to the enjoyment of eating. ${ }^{22}$ The role of informal caregivers and the home meal-delivery professionals is therefore key and should be emphasised with a view to encouraging home-dwelling older people to continue eating well. ${ }^{23} 26$ A more personalised range of meal choices is another avenue that could be explored to help prevent malnutrition. Yet, literature reports indicate that among all the activities performed by formal and informal caregivers, and regardless of the level of autonomy of the elderly person, help with eating is not a priority, and is always ranked below toileting and dressing. ${ }^{27}$ This raises the question of whether help with eating should be proposed systematically whenever home-help is provided for older adults living at home. In addition, prevention of malnutrition could encompass programmes aimed at helping the elderly person to prepare their meals at home.

In addition to providing a quantitative and qualitative snapshot of food intake, our results may also help to inform existing instruments for the early detection of malnutrition. ${ }^{11} 1328$ Indeed, the SEFI tool provides a quantitative, but not a qualitative evaluation. By incrementing existing tools, it might be possible to take action before the state of malnutrition is constituted, with a view to screening for and detecting at-risk behaviours.

\section{Strengths and limitations}

Using an exploratory approach in the home, our study focuses on community-dwelling older adults before the onset of a documented state of frailty. To the best of our knowledge, this aspect of nutrition risk has not been widely investigated in the literature and represents a strength of our study. Conversely, our study has several limitations that deserve to be underlined. First, the data 
Table 3 Socioeconomic characteristics of 605 home-dwelling study participants in 2015

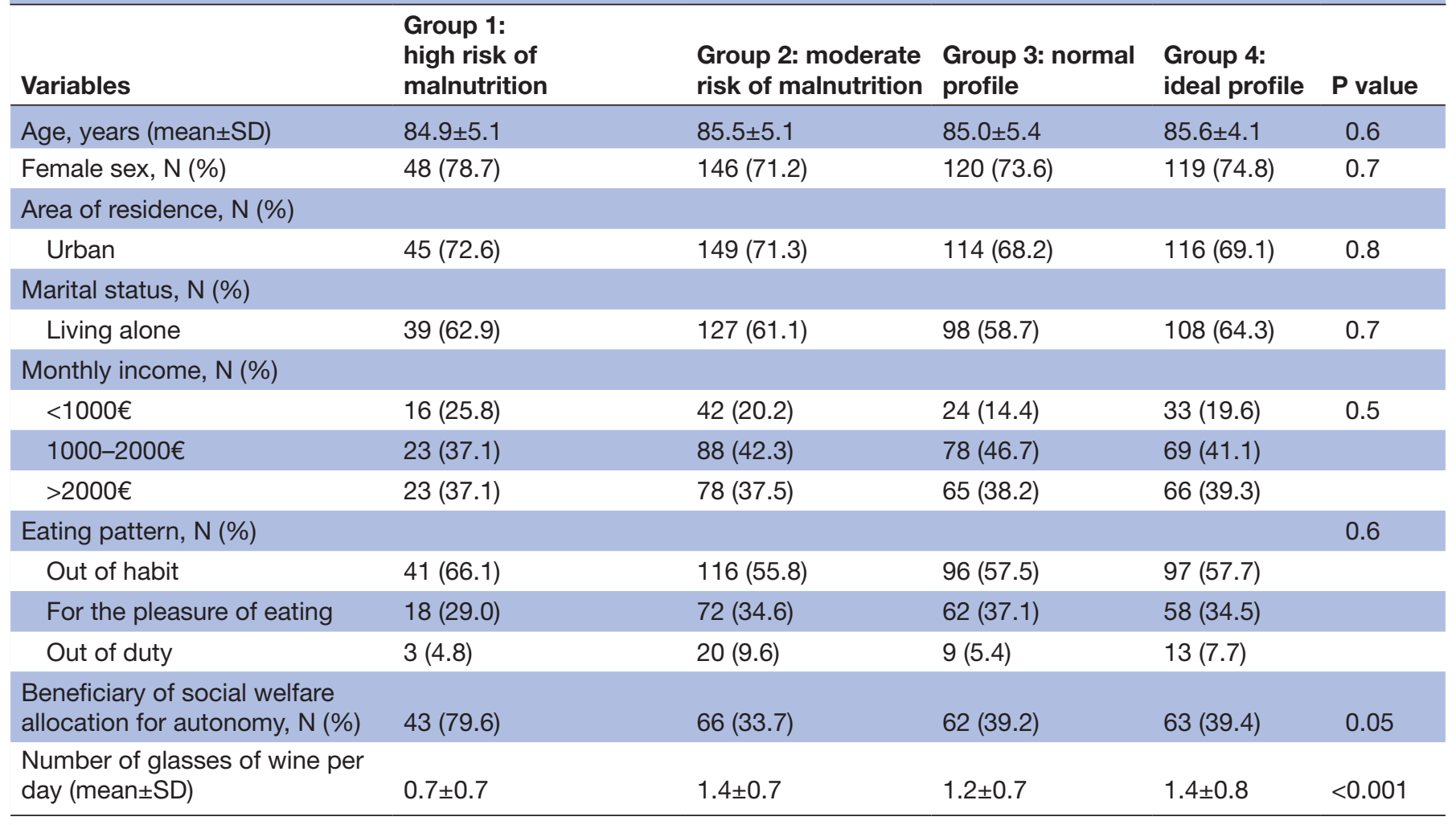

Data are presented as mean \pm SD or number (percentage).

collection was performed over 3 days only. A longer data collection period might have made it possible to perform panel data analysis to investigate intraindividual variability (ie, passage from one group to another). However, the duration chosen here is that generally applied in studies relating to food intake. ${ }^{13}$ Second, our study population is subject to a selection bias inherent to the study methodology. Indeed, the individuals most exposed to risk, such as isolated and frail elderly with precarious financial status, do not generally have access to paying homehelp services. Third, the use of MFA identifies different profiles, but does not explain the totality of the variance, with the percentage of variation explained ranging between $10 \%$ and $30 \%$. However, the findings do reveal profiles that are coherent with the reality of the data observed in the field, and also in line with existing literature. Lastly, we cannot rule out the possible impact of other factors known to influence quantity and quality of food consumed in community-dwelling older adults, such as food insecurity, disease type and severity, polypharmacy or oral hygiene. ${ }^{29-31}$

\section{CONCLUSION}

Our study using MFA identified different eating profiles among community-dwelling older adults. These results could prompt further reflection on the type of advice and aid that might be most appropriate and attractive for older adults. Indeed, measures aimed at preventing malnutrition should encompass both quantitative advice, as well as qualitative educational measures to promote enjoyment of eating. To go further, it will be interesting, in light of our results, to target specific prevention programmes for those most at risk (group 1), by helping them to rediscover the pleasure in eating, and by encouraging good eating habits.

Contributors M-AS: data management, design of the study, statistical analysis, interpretation of findings, preparation of manuscript writing and reviewing all versions, agreement to be accountable for all aspects of the work. DA: interpretation of findings, drafting the work, reviewing of final version, agreement to be accountable for all aspects of the work. YM and AL: design of the work, drafting the work, acquisition of data, reviewing of final version, agreement to be accountable for all aspects of the work. RM, conception of the work, revising the work, reviewing of final version, agreement to be accountable for all aspects of the work. SS: conception of the work, preparation of manuscript, reviewing of final version, agreement to be accountable for all aspects of the work.

Funding The authors have not declared a specific grant for this research from any funding agency in the public, commercial or not-for-profit sectors.

Competing interests None declared.

Patient consent for publication Next of kin consent obtained.

Provenance and peer review Not commissioned; externally peer reviewed.

Data sharing statement All available data can be obtained by contacting the corresponding author.

Open access This is an open access article distributed in accordance with the Creative Commons Attribution Non Commercial (CC BY-NC 4.0) license, which permits others to distribute, remix, adapt, build upon this work non-commercially, and license their derivative works on different terms, provided the original work is properly cited, appropriate credit is given, any changes made indicated, and the use is non-commercial. See: http://creativecommons.org/licenses/by-nc/4.0/. 


\section{REFERENCES}

1. Bauer J, Biolo G, Cederholm T, et al. Evidence-based recommendations for optimal dietary protein intake in older people: a position paper from the PROT-AGE Study Group. J Am Med Dir Assoc 2013;14:542-59.

2. Hébuterne $X$. Malnutrition of the elderly. Nutr Clin Métabolisme 2006;20:S55-9.

3. Schneider SM, Veyres P, Pivot X, et al. Malnutrition is an independent factor associated with nosocomial infections. Br J Nutr 2004;92:105-11.

4. Wu LW, Chen WL, Peng TC, et al. All-cause mortality risk in elderly individuals with disabilities: a retrospective observational study. BMJ Open 2016;6:e011164.

5. Shafiee G, Ostovar A, Heshmat R, et al. Bushehr Elderly Health $(\mathrm{BEH})$ programme: study protocol and design of musculoskeletal system and cognitive function (stage II). BMJ Open 2017;7:e013606.

6. Roberts SB, Fuss P, Heyman MB, et al. Control of food intake in older men. JAMA 1994;272:1601-6.

7. Constans T, malnutrition ERev Prat 2003;53:263-7.

8. Allès B, Samieri C, Féart C, et al. Dietary patterns: a novel approach to examine the link between nutrition and cognitive function in older individuals. Nutr Res Rev 2012;25:207-22.

9. Trichopoulou A, Kouris-Blazos A, Wahlqvist ML, et al. Diet and overall survival in elderly people. BMJ 1995;311:1457-60.

10. Abd-El-Gawad WM, Abou-Hashem RM, El Maraghy MO, et al. The validity of Geriatric Nutrition Risk Index: simple tool for prediction of nutritional-related complication of hospitalized elderly patients. Comparison with Mini Nutritional Assessment. Clin Nutr 2014;33:1108-16.

11. Bouteloup C, Thibault R. Decision tree for nutritional care. Nutr Clin Métabolisme 2014;28:52-6.

12. Guigoz Y. The Mini Nutritional Assessment (MNA) review of the literature--What does it tell us? J Nutr Health Aging 2006;10:466-85.

13. Thibault R, Goujon N, Le Gallic E, et al. Use of 10-point analogue scales to estimate dietary intake: a prospective study in patients nutritionally at-risk. Clin Nutr 2009;28:134-40.

14. Gaffney-Stomberg E, Insogna KL, Rodriguez NR, et al. Increasing dietary protein requirements in elderly people for optimal muscle and bone health. J Am Geriatr Soc 2009;57:1073-9.

15. Surdykowski AK, Kenny AM, Insogna KL, et al. Optimizing bone health in older adults: the importance of dietary protein. Aging Health 2010;6:345-.
16. Fritz K, Elmadfa I. Quality of nutrition of elderly with different degrees of dependency: elderly living in private homes. Ann Nutr Metab 2008;52(Suppl 1):47-50.

17. Clum G, Gustat J, O'Malley K, et al. Factors Influencing Consumption of Fruits and Vegetables in Older Adults in New Orleans, Louisiana. $J$ Nutr Health Aging 2016;20:678-84.

18. Woo J. Nutritional strategies for successful aging. Med Clin North Am 2011;95:477-93.

19. Chernoff R. Nutrition and health promotion in older adults. J Gerontol A Biol Sci Med Sci 2001;56(Spec No 2):47-53.

20. Andreeva V, Allès B, Feron G, et al. Sex-Specific Sociodemographic Correlates of Dietary Patterns in a Large Sample of French Elderly Individuals. Nutrients 2016;8:484.

21. Lorenzo-López L, Maseda A, de Labra C, et al. Nutritional determinants of frailty in older adults: A systematic review. BMC Geriatr 2017;17:108.

22. Pepersack T. Is deterioration of the sensory functions and appetite a fatality among the elderly? Nutr Clin Métabolisme 2004;18:189-97.

23. Bauduceau B, Belmejdoub G, Dognon C, et al. Nutrition in the elderly. Médecine Mal Métaboliques 2017;11:223-7.

24. Buys DR, Roth DL, Ritchie CS, et al. Nutritional risk and body mass index predict hospitalization, nursing home admissions, and mortality in community-dwelling older adults: results from the UAB Study of Aging with 8.5 years of follow-up. J Gerontol A Biol Sci Med Sci 2014;69:1146-53.

25. Sulmont-Rossé C, Maître I, Issanchou S. Age, chemo-sensorial perception and food preferences. gérontologie Société 2010;33:87-106

26. Chanial P, Gaglio G. « Aidons les aidants. A Mutualist Initiative Against Market Dependency. Rev mauss 2013;41:121-39.

27. Imbert F, Lang PO, Meyer N, et al. [Home living conditions in Alsace of the disabled elderly aged 75 years and more]. Rev Epidemiol Sante Publique 2005;53:153-65.

28. Thibault R, Guex E, Pichard C. How to assess nutritional status and risk? What intervention strategy? SFNEP Education and Clinical Practice Committee 2012:55-72.

29. Van Lancker A, Verhaeghe S, Van Hecke A, et al. The association between malnutrition and oral health status in elderly in long-term care facilities: a systematic review. Int J Nurs Stud 2012;49:1568-81.

30. Little MO. Updates in nutrition and polypharmacy. Curr Opin Clin Nutr Metab Care 2018;21:4-9.

31. Grammatikopoulou MG, Gkiouras K, Theodoridis X, et al. Food insecurity increases the risk of malnutrition among communitydwelling older adults. Maturitas 2019;119:8-13. 